\title{
Gas transport properties of Teflon AF2400/ceramic composite hollow fiber membranes in dissolved gas-in-oil extraction
}

\author{
Liang-Chih Ma ${ }^{a}$, Chuan Chen ${ }^{b}$, Chien-Hua Chen ${ }^{c}$, Kuo-Lun Tung ${ }^{c}$, Jerry Y.S. Lin ${ }^{a}$ *
}

\begin{abstract}
${ }^{a}$ School for Engineering of Matter, Transport and Energy, Arizona State University, Tempe, AZ 85287, USA

${ }^{\mathrm{b}}$ Global Energy Interconnection Research Institute Co., Ltd., P. R. China

${ }^{\mathrm{c}}$ Department of Chemical Engineering, National Taiwan University, Taiwan (R.O.C)
\end{abstract}

*To whom all correspondence should be addressed.

Contact information:

Prof. Jerry Y.S. Lin

School for Engineering of Matter, Transport and Energy, Arizona State University, Tempe, AZ 85287, USA;

Tel.: + 14804588215

E-mail:jerry.lin@asu.edu 


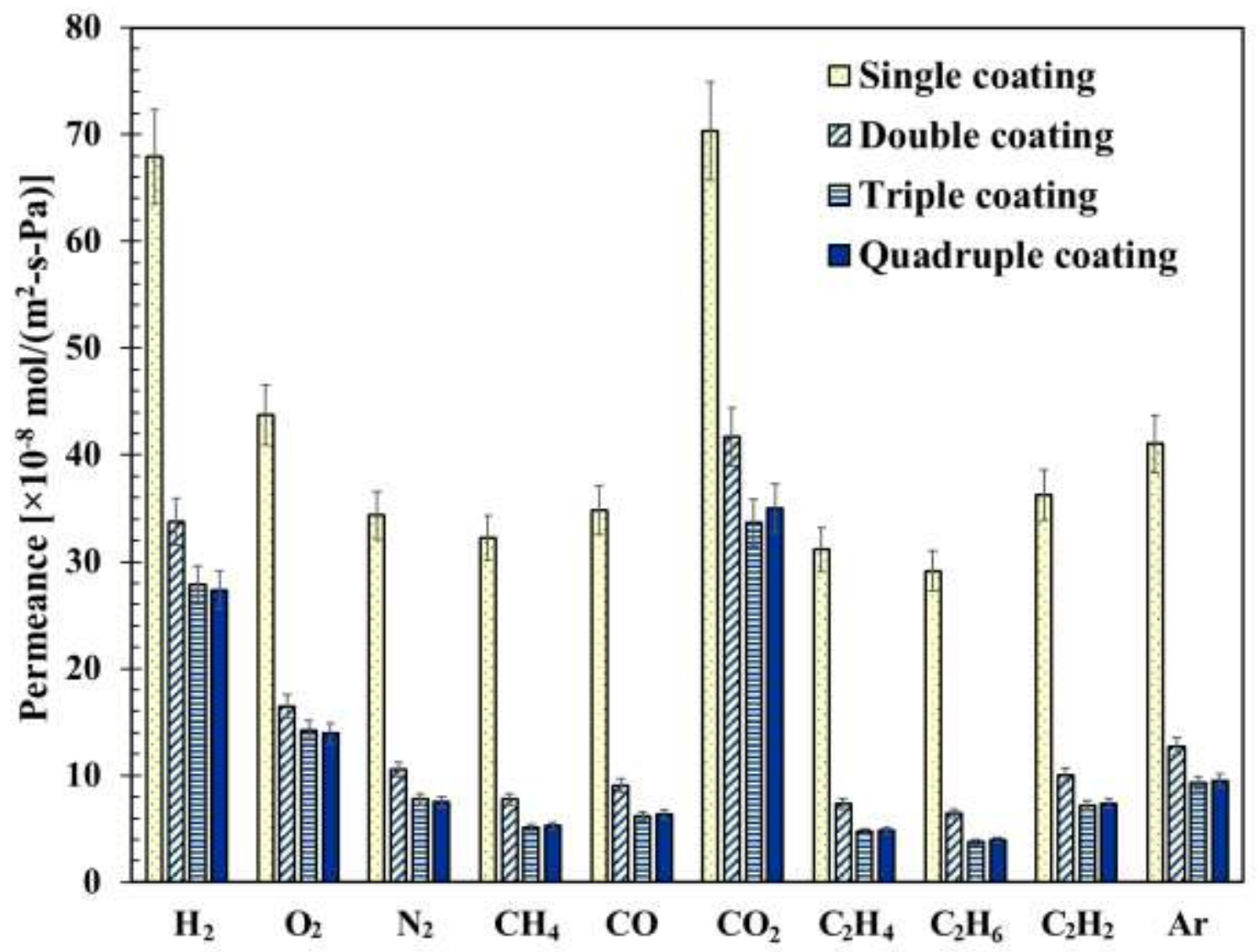

Figure S1. A comparison of gas permeances of $\alpha-\mathrm{Al}_{2} \mathrm{O}_{3}$ hollow fiber supports with various numbers of Teflon AF2400-coatings. 


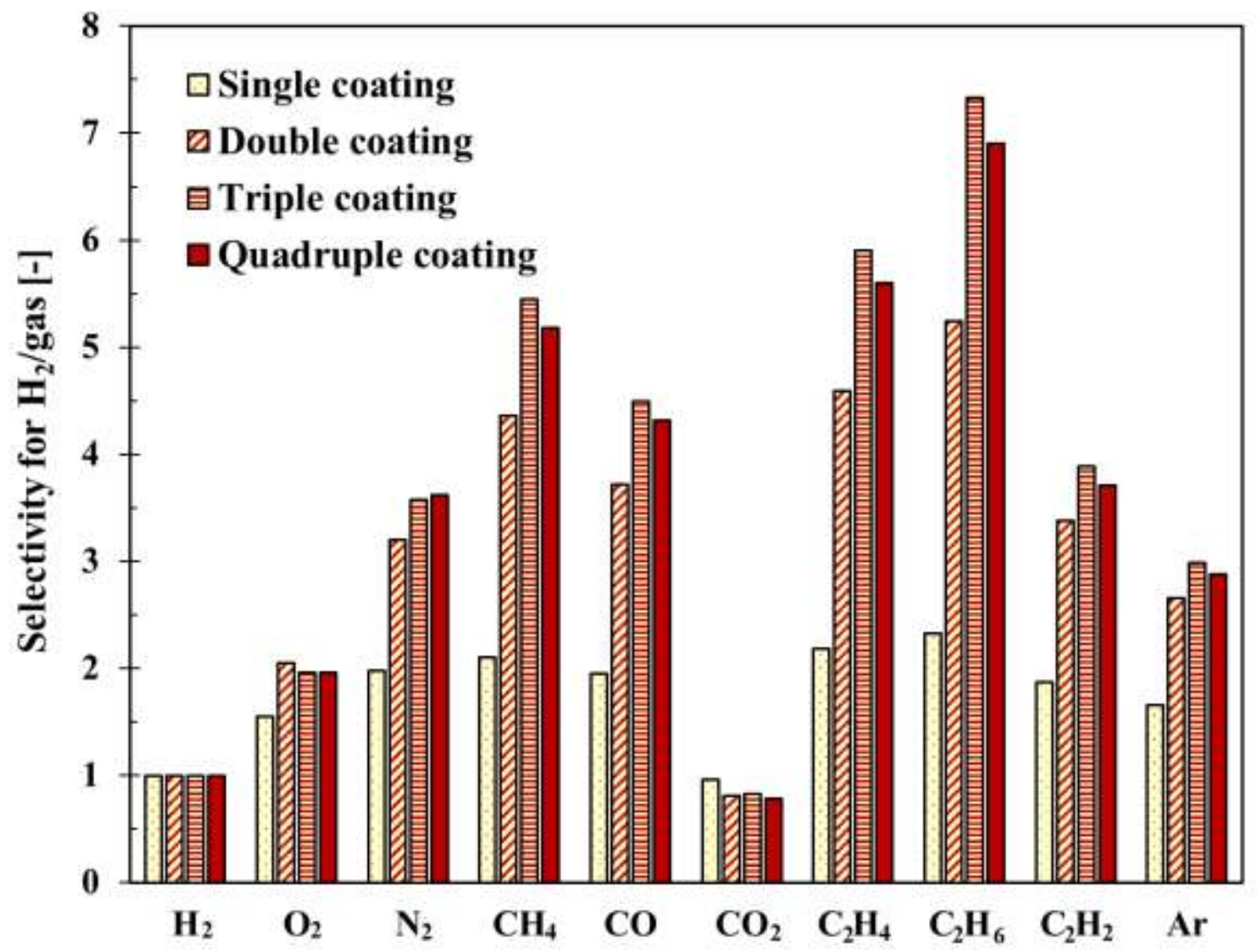

Figure S2. A comparison of selectivities for $\mathrm{H}_{2} /$ gas of $\alpha-\mathrm{Al}_{2} \mathrm{O}_{3}$ hollow fiber supports with various numbers of Teflon AF2400-coatings. 


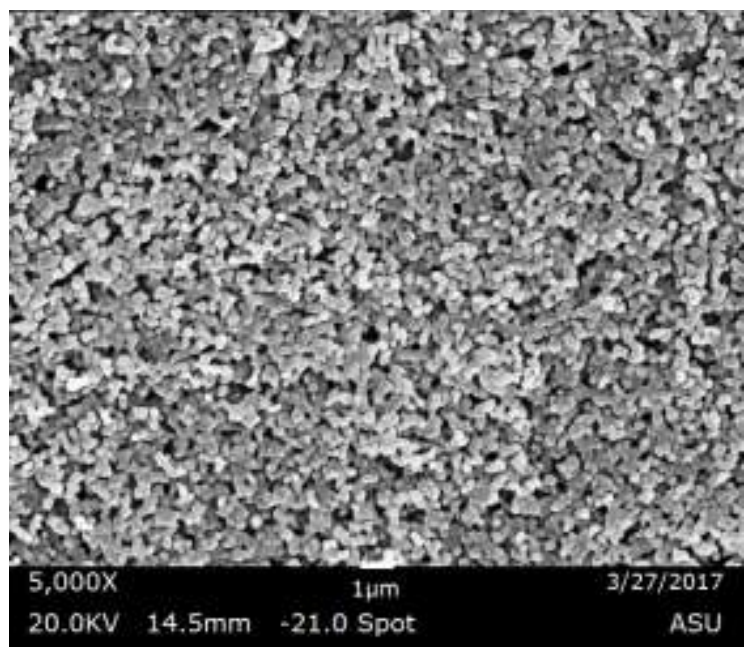

(a) Bare $\alpha-\mathrm{Al}_{2} \mathrm{O}_{3}$ support

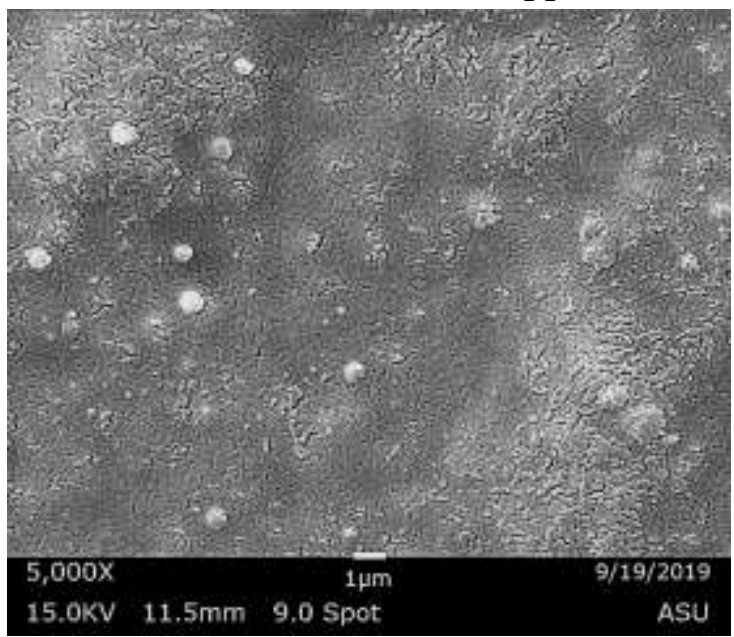

(c) Double coating

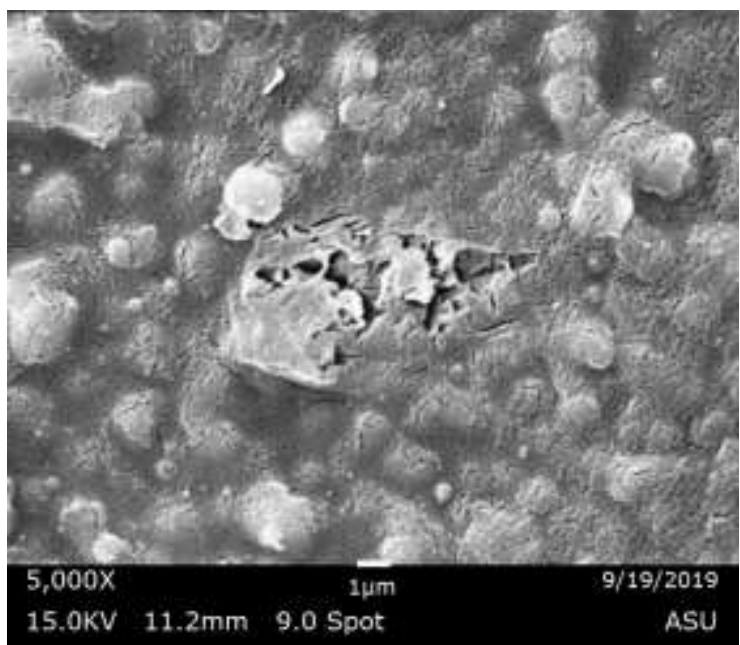

(b) Single coating

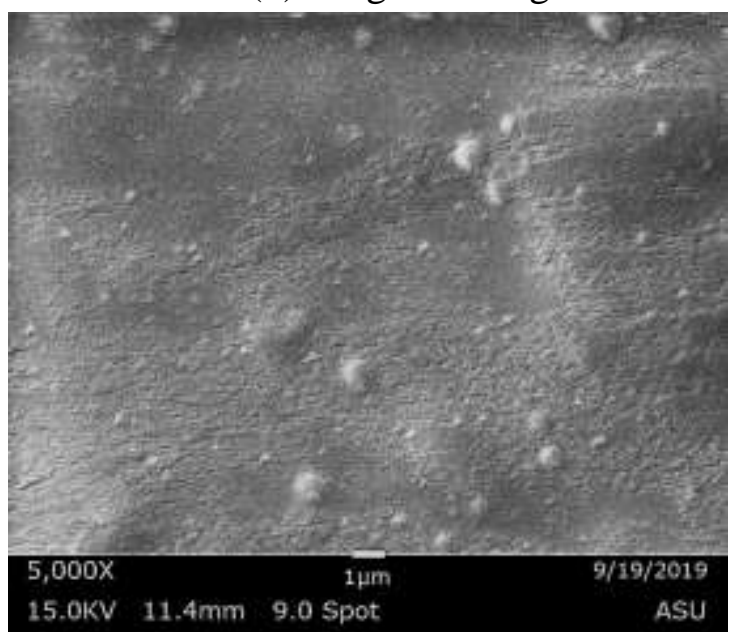

(d) Triple coating

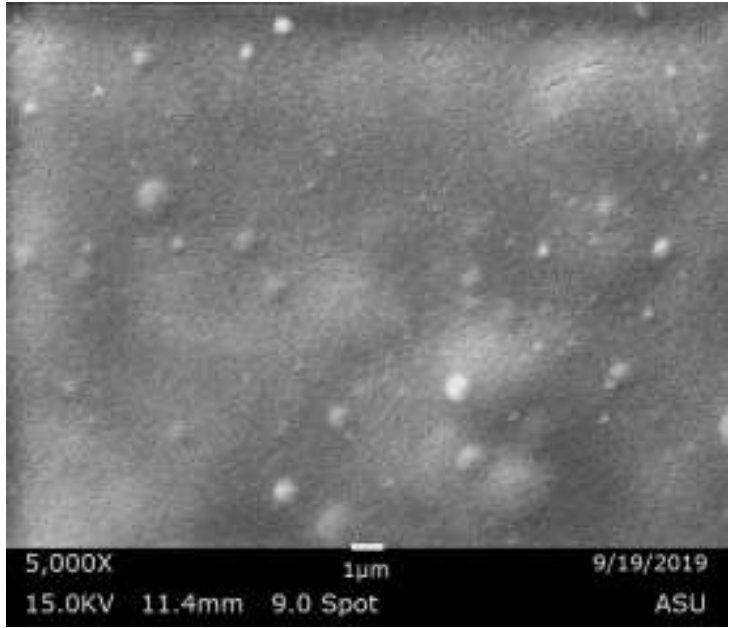

(e) Quadruple coating

Figure S3. SEM images of the surfaces of $\alpha-\mathrm{Al}_{2} \mathrm{O}_{3}$ hollow fiber supports with various numbers of Teflon AF2400-coatings. Magnification: 5K. 
Table S1. Properties of Kunlun KI25X transformer oil.

\begin{tabular}{|c|c|}
\hline Property & Value \\
\hline Density at $20^{\circ} \mathrm{C}\left[\mathrm{kg} / \mathrm{m}^{3}\right]^{\mathrm{a}}$ & 877.4 \\
\hline Kinematic viscosity at $40^{\circ} \mathrm{C}\left[\mathrm{mm}^{2} / \mathrm{s}\right]^{\mathrm{a}}$ & 9.65 \\
\hline Kinematic viscosity at $-10^{\circ} \mathrm{C}\left[\mathrm{mm}^{2} / \mathrm{s}\right]^{\mathrm{a}}$ & 157.4 \\
\hline Pour point $\left[{ }^{\circ} \mathrm{C}\right]^{\mathrm{a}}$ & -42 \\
\hline Flash point $\left[{ }^{\circ} \mathrm{C}\right]^{\mathrm{a}}$ & 138 \\
\hline Surface tension $[\mathrm{mN} / \mathrm{m}]^{\mathrm{a}}$ & 41 \\
\hline Acid value $[\mathrm{mg} \mathrm{KOH} / \mathrm{g} \text { oil }]^{\mathrm{a}}$ & 0.009 \\
\hline Aniline point $\left[{ }^{\circ} \mathrm{C}\right]^{\mathrm{a}}$ & 76.3 \\
\hline Breakdown voltage $[\mathrm{kV}]^{\mathrm{a}}$ & 55 \\
\hline Average molecular weight $[\mathrm{g} / \mathrm{mol}]^{\mathrm{b}}$ & 384 \\
\hline Vapor pressure at $30^{\circ} \mathrm{C}[\mathrm{Pa}]^{\mathrm{c}}$ & 0.016 \\
\hline Vapor pressure at $50^{\circ} \mathrm{C}[\mathrm{Pa}]^{\mathrm{c}}$ & 3.87 \\
\hline Vapor pressure at $70^{\circ} \mathrm{C}[\mathrm{Pa}]^{\mathrm{c}}$ & 40.5 \\
\hline Vapor pressure at $90^{\circ} \mathrm{C}[\mathrm{Pa}]^{\mathrm{c}}$ & 149 \\
\hline
\end{tabular}

a Obtained from the manufacturer.

${ }^{\mathrm{b}}$ Adopted from the report by Rose [1].

${ }^{c}$ Adopted from the report by Hong et al. [2]. 


\section{Derivation of the correlation function between the equilibrium level and the gas permeance for membrane-based dissolved gas extractors}

In our study, equilibrium level is defined as the ratio of the partial pressure of the gas in the closed permeate loop to the equilibrium partial pressure in the headspace. To obtain a better understanding of the correlation between the equilibrium level and the gas permeance in the membrane-based dissolved gas-in-oil extraction process, an equation used to describe the equilibrium level as function of gas permeance and permeation time was derived. Nomenclature of the parameters used in derivation is given in Table S2.

Table S2. Nomenclature of the parameters used in derivation.

\begin{tabular}{|r|l|}
\hline $\mathrm{q}$ & $:$ volume of the permeated dissolved gas \\
\hline $\mathrm{t}$ & $:$ Permeation time \\
\hline $\mathrm{F}$ & $:$ permeance of the dissolved gas \\
\hline $\mathrm{A}_{\mathrm{m}}$ & $:$ membrane area \\
\hline $\mathrm{V}$ & $:$ permeate loop volume \\
\hline $\mathrm{P}_{2}$ & $:$ partial pressure of the dissolved gas in the permeate side at $\mathrm{t}$ \\
\hline $\mathrm{P}_{1}$ & $:$ equilibrium partial pressure of the dissolved gas in the headspace \\
\hline $\mathrm{P}_{0}$ & $:$ partial pressure of the dissolved gas in the permeate side at $\mathrm{t}=0$ \\
\hline $\mathrm{P}_{\text {per }}$ & $:$ total pressure in the permeate side \\
\hline $\mathrm{EL}$ & $:$ equilibrium level \\
\hline
\end{tabular}

Based on Fick's law, the volume flow rate of the dissolved gas through the membrane can be described by Eq. S1.

$$
\frac{\mathrm{dq}}{\mathrm{dt}}=\mathrm{F} \cdot \mathrm{A}_{\mathrm{m}} \cdot\left(\mathrm{P}_{1}-\mathrm{P}_{2}\right)
$$

An infinitely small partial pressure of the dissolved gas in the permeate side $\left(\mathrm{dP}_{2}\right)$ at a constant total pressure $\left(\mathrm{P}_{\mathrm{per}}\right)$, permeate loop volume $(\mathrm{V})$ and temperature is given by Eq. S2.

$$
\mathrm{dP}_{2}=\frac{\mathrm{P}_{\mathrm{per}}}{\mathrm{V}} \cdot \mathrm{dq}
$$

By substituting Eq. S2 into Eq. S1, an ordinary differential equation for the dissolved gas partial pressure is obtained as shown in Eq. S3.

$$
\frac{d P_{2}}{d t}=\frac{P_{\text {per }}}{V} \cdot F \cdot A_{m} \cdot\left(P_{1}-P_{2}\right)
$$

After integrating the differential equation from $\mathrm{P}_{2}=\mathrm{P}_{0}$ at $\mathrm{t}=0$ to $\mathrm{P}_{2}=\mathrm{P}_{2}$ at $\mathrm{t}=\mathrm{t}, \mathrm{P}_{2}$ as a function of $\mathrm{F}$ and $\mathrm{t}$ is given by Eq. S4. 


$$
P_{2}=\left(P_{1}-P_{0}\right) \cdot\left(1-\exp \left[-\frac{P_{p e r}}{V} \cdot F \cdot A_{m} \cdot t\right]\right)+P_{0}
$$

Since the term value of $\exp \left[-\frac{P_{p e r}}{V} \cdot F \cdot A_{m} \cdot t\right]$ approaches to zero with increasing $\mathrm{t}, \mathrm{P}_{2}$ will become $\mathrm{P}_{1}$ when system equilibrium is reached. $\mathrm{As}_{\mathrm{P}} \mathrm{P}_{0}$ is zero, the equilibrium level (EL) as function of gas permeance and permeation time can be simply expressed by Eq. S5.

$$
\mathrm{EL}=\frac{\mathrm{P}_{2}}{\mathrm{P}_{1}}=1-\exp \left[-\frac{\mathrm{P}_{\mathrm{per}}}{\mathrm{V}} \cdot \mathrm{F} \cdot \mathrm{A}_{\mathrm{m}} \cdot \mathrm{t}\right]
$$


Table S3. Henry's law solubility constants for dissolved gases at $29^{\circ} \mathrm{C}$ and $1 \mathrm{~atm}$.

\begin{tabular}{lccccccc}
\hline & \multicolumn{7}{c}{ Henry's law solubility constant } \\
\cline { 2 - 8 } & $\mathrm{H}_{2}$ & $\mathrm{CH}_{4}$ & $\mathrm{CO}$ & $\mathrm{CO}_{2}$ & $\mathrm{C}_{2} \mathrm{H}_{4}$ & $\mathrm{C}_{2} \mathrm{H}_{6}$ & $\mathrm{C}_{2} \mathrm{H}_{2}$ \\
\hline Average & 0.075 & 0.692 & 0.173 & 0.965 & 3.433 & 6.155 & 2.334 \\
Standard deviation & $0.4 \%$ & $1.3 \%$ & $0.9 \%$ & $1.9 \%$ & $1.9 \%$ & $1.5 \%$ & $1.7 \%$ \\
\hline
\end{tabular}

* The values were calculated by the experimental data in Figure 5. 


\section{Verification of the derived correlation function by the equilibrium tests}

To verify the correlation function of Eq. S5, the equilibrium tests were conducted using a membrane-based dissolved gas extractor. The layout of the extractor is similar to that of the extraction system. The main difference is that the permeate loop of the extractor is closed and involves a micro pump (Series 8000 air pump, Smart Products) which circulates the permeated gas to mitigate the effect of concentration polarization. The system parameters are given in Table S4. Before each test, the permeate loop was purged with Ar for 20 minutes to remove residual characteristic gases in the permeate side. In the tests, both pressures in the headspace and the permeate loop were kept at $1 \mathrm{~atm}$ and the standard gas mixture was kept bubbling into the oil to ensure dynamic equilibrium in the oil tank. The gas concentrations in the permeate loop at various permeation times were measured by the transformer oil gas analysis system. The profiles of gas concentrations as a function of permeation time can be obtained by each result of an individual test. The operating conditions are given in Table S5.

Table S4. System parameters of the membrane-based dissolved gas extractor.

\begin{tabular}{ll}
\hline Oil & Kunlun KI25X Transformer Oil \\
Tank capacity & $5.0 \mathrm{~L}$ \\
Volume of oil & $3.5 \mathrm{~L}$ \\
Volume of headspace & $1.5 \mathrm{~L}$ \\
Membrane module capacity & $19 \mathrm{~cm}^{3}$ \\
Hollow fiber membrane length & $20 \mathrm{~cm}$ \\
O.D. of the hollow fiber membrane & $1.2 \mathrm{~mm}$ \\
I.D. of the hollow fiber membrane & $0.8 \mathrm{~mm}$ \\
Number of hollow fiber membrane in the module & 1 \\
Effective permeation area of the membrane & $7.6 \mathrm{~cm}^{2}$ \\
Volume of permeate loop & $15 \mathrm{~cm}^{3}$ \\
\hline
\end{tabular}

Table S5. Operating conditions for the equilibrium tests.

\begin{tabular}{ll}
\hline Headspace pressure & 1 atm $(0 \mathrm{barg})$ \\
Permeate pressure & 1 atm $(0 \mathrm{barg})$ \\
Circulating flow rate & $322 \mathrm{ml} / \mathrm{min}$ \\
Standard gas mixture bubbling rate & $19.1 \mathrm{ml} / \mathrm{min}$ \\
Operating temperature & $29^{\circ} \mathrm{C}$ \\
Oil feed flow rate & $122 \mathrm{ml} / \mathrm{min}$ \\
Liquid velocity in the retentate side & $2.63 \mathrm{~cm} / \mathrm{s}$ \\
Gas velocity in the permeate side & $1042 \mathrm{~cm} / \mathrm{s}$ \\
\hline
\end{tabular}


The Teflon AF2400/ $\gamma-\mathrm{Al}_{2} \mathrm{O}_{3} / \alpha-\mathrm{Al}_{2} \mathrm{O}_{3}$ composite membrane after 220 hours in the dissolved gas extraction test was characterized by the equilibrium tests. Figure S4 presents the experimental results and simulation profiles of equilibrium level as a function of permeation time for various dissolved gases. Please notice that the values of gas permeances were adopted from the data at 220 hours in the dissolved gas extraction test and the effect of physical aging of the membrane on gas permeances was assumed to be neglected. As observed, the simulation profiles for various dissolved gases match the experimental results well. Therefore, by taking advantage of the correlation function, the equilibrium partial pressures of gases in the headspace can be simply estimated once the partial pressures of gases in the permeate side and the permeation time are measured. Combined with the use of Henry's law solubility constants, the dissolved gas concentrations in the oil can be obtained. 


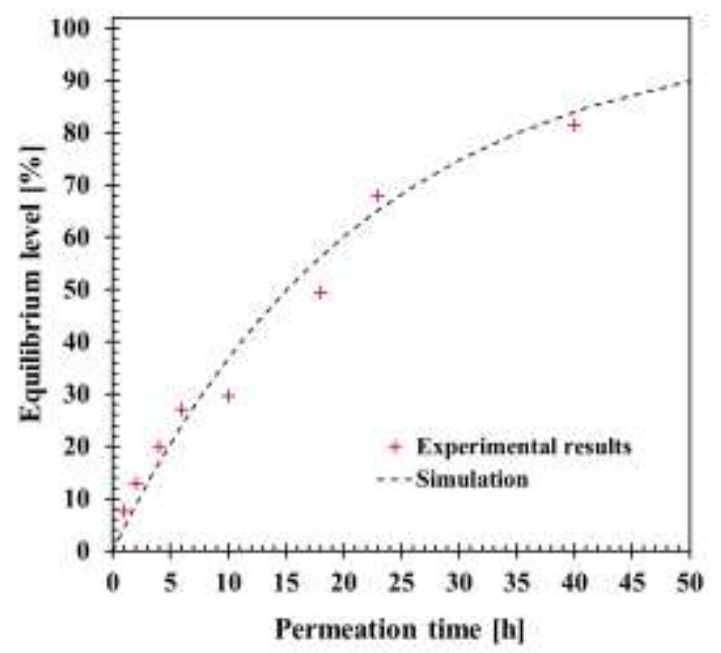

(a) $\mathrm{H}_{2}$

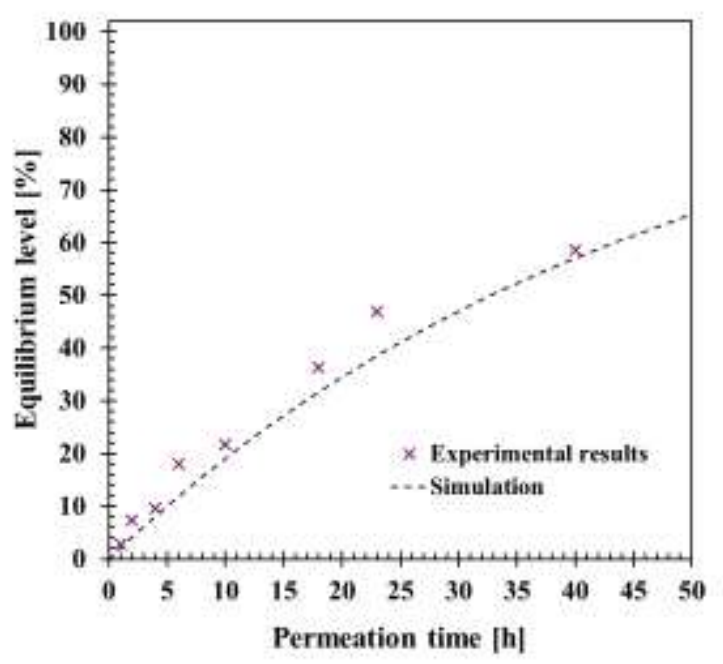

(c) $\mathrm{CO}$

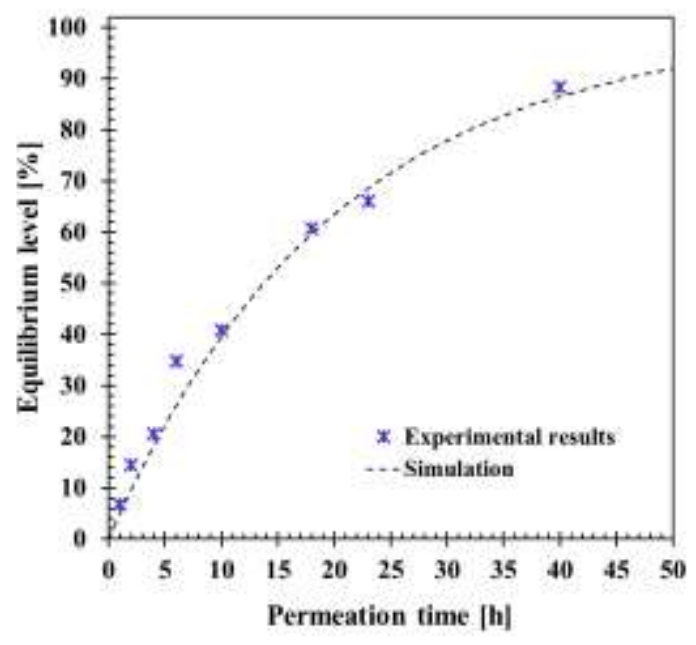

(b) $\mathrm{CH}_{4}$

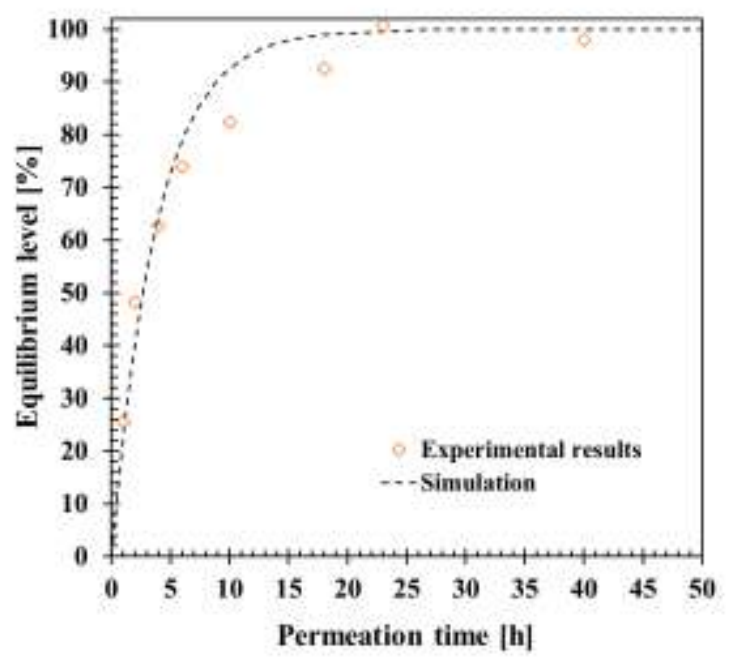

(d) $\mathrm{CO}_{2}$ 


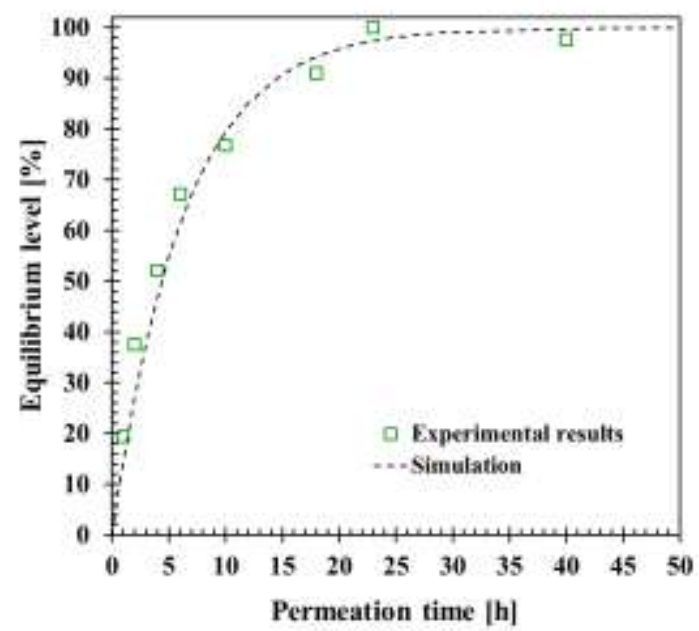

(e) $\mathrm{C}_{2} \mathrm{H}_{4}$

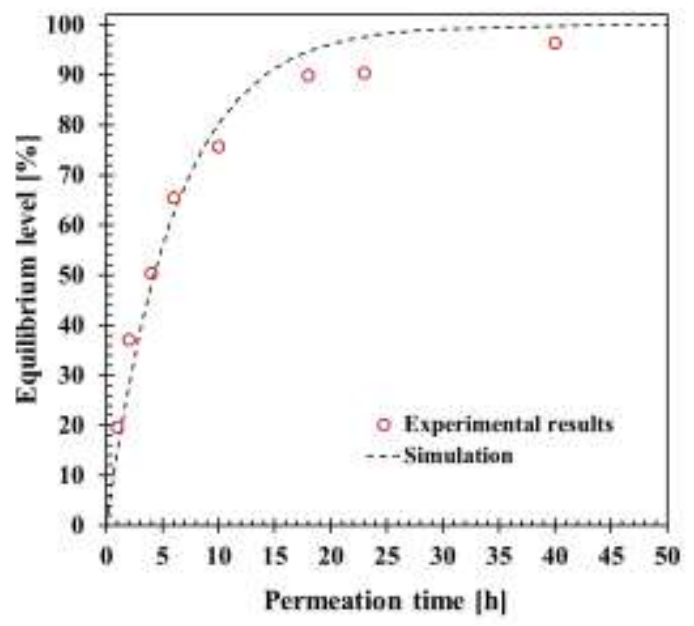

(f) $\mathrm{C}_{2} \mathrm{H}_{6}$

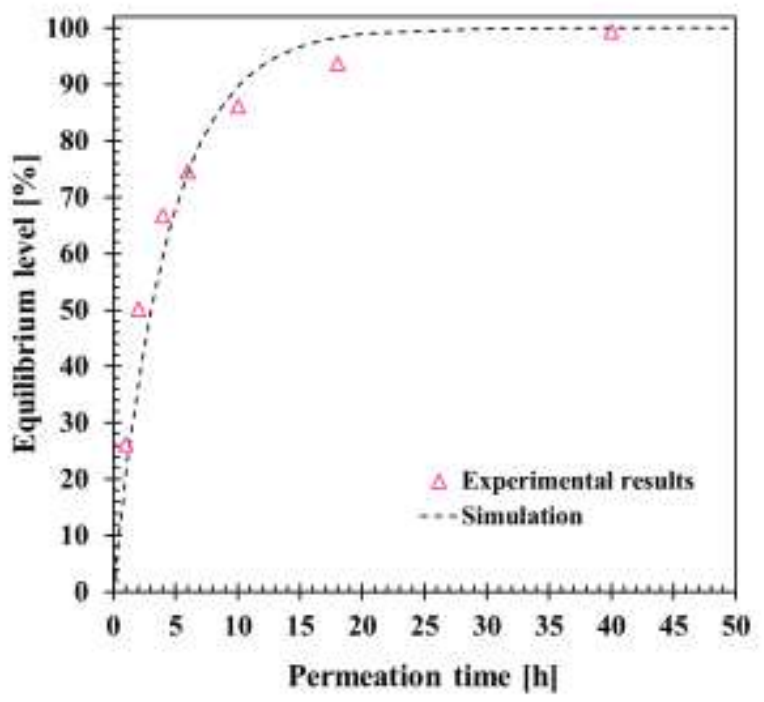

(g) $\mathrm{C}_{2} \mathrm{H}_{2}$

Figure S4. Experimental and simulation profiles of equilibrium level as a function of permeation time for various dissolved gases. 
Table S6. A comparison between the theoretical values and the experimental values of mass percentage of Teflon AF2400/ $\gamma-\mathrm{Al}_{2} \mathrm{O}_{3} / \alpha-\mathrm{Al}_{2} \mathrm{O}_{3}$ composite hollow fiber membranes.

\begin{tabular}{cccccc}
\hline \multirow{2}{*}{ Composite membrane } & $\begin{array}{c}\text { Thickness } \\
{[\mu \mathrm{m}]}\end{array}$ & $\begin{array}{c}\text { Porosity } \\
{[\%]}\end{array}$ & $\begin{array}{c}\text { Density } \\
{\left[\mathrm{g} / \mathrm{cm}^{3}\right]}\end{array}$ & \multicolumn{2}{c}{ Mass percentage [\%] } \\
\cline { 5 - 6 } Teflon AF2400 layer & 1 & 0 & $1.67^{\mathrm{a}}$ & 0.53 & 0.42 \\
\hline$\gamma-\mathrm{Al}_{2} \mathrm{O}_{3}$ layer & 3 & $53^{\mathrm{b}}$ & $3.65^{\mathrm{c}}$ & 1.63 & \multirow{2}{*}{99.58} \\
\hline$\alpha-\mathrm{Al}_{2} \mathrm{O}_{3}$ support & 220 & 57 & $3.99^{\mathrm{c}}$ & 97.84 & \\
\hline
\end{tabular}

adopted from the report by Tiwari et al. [3]

${ }^{\mathrm{b}}$ Adopted from the report by Saha et al. [4]

${ }^{c}$ Adopted from the report by Levin and Brandon [5]

\section{References}

[1] Rouse, T. O. Mineral insulating oil in transformers. IEEE Electr. Insul. Mag. 1998, 14 (3), 616.

[2] Hong, B.; Lv, S.; Liu, Q.; Hou, J.; Ji, Y.; Gao, Z.; Gao, J.; Hu, J. A simple method to evaluate the vapor pressure of transformer oil at various temperatures. 7th Int. conf. energy env. prot. 2018, 170, 305-314.

[3] Tiwari, R. R.; Smith, Z. P.; Lin, H.; Freeman, B. D.; Paul, D. R. Gas permeation in thin films of "high free-volume" glassy perfluoropolymers: Part I. Physical aging. Polymer 2014, 55 (22), 5788-5800.

[4] Saha, D.; Mistry, K. K.; Giri, R.; Guha, A.; Sensgupta, K. Dependence of moisture absorption property on sol-gel process of transparent nano-structured $\gamma-\mathrm{Al}_{2} \mathrm{O}_{3}$ ceramics. Sens. Actuators B Chem. 2005, 109 (2), 363-366.

[5] Levin, I.; Brandon, D. Metastable alumina polymorphs: crystal structures and transition sequences. J. Am. Ceram. Soc. 1998, 81 (8), 1995-2012. 